\title{
Self-Authoring the Meaning of Student Teaching in China: Impacts on First-Year Teaching Practices
}

\section{Hillary Parkhouse, Alison McGlinn Turner, Stephanie Konle and Xue Lan Rong}

University of North Carolina at Chapel Hill

The growing cultural and linguistic diversities in Western countries and rapid globalization have put urgent demands on K-16 schools in terms of developing strategies to accommodate these changes. These are particularly pressing in U.S. public schools where over one in five students are now the children of immigrants (Rong \& Preissle, 2009). One of the critical issues for schools is to prepare pre-service and in-service teachers to work effectively with their diverse student populations. Despite increasing demands for teachers to teach for equity, diversity, and global interconnectedness, many teacher education programs are not producing teachers with the sufficient knowledge and skills to do so (Merryfield, 2000; Zhao, 2010).

The majority of pre-service teachers in the U.S. are White, middle-class, and monolingual speakers of English with limited understanding of the diverse backgrounds and cultural knowledge of students who are different from them (Sharma, Phillion, \& Malewski, 2011). These authors argued that since many pre-service teachers do not engage in the social, historical, and political issues that relate directly to inequality and lack of opportunities among different cultural groups in schools and society, teacher preparation programs should provide study abroad opportunities for cross-cultural field experiences. Teaching overseas can result in changes to pre-service teachers' perceptions of self and others, hence challenging their assumptions and biases in order to create a classroom environment sensitive to the cultural backgrounds and academic needs of all students (Shiveley \& Misco, 2015; Suarez, 2003).

The increased calls for global and cross-cultural competence training for teachers have led many teacher education programs in the U.S. as well as other countries to offer student teaching abroad opportunities (Barnhart, 1989; Cushner \& Mahon, 2002; Malewski \& Phillion, 2008; Reyes, Quezada, \& Alfaro, 2007; Willard-Holt, 2001; Zhao, Meyers, \& Meyers, 2009). Cwick and Benton (2009) reported that student teaching abroad has been considered one of the most effective practices for schools and colleges of education as these programs can provide rich and transformative intercultural experiences for teacher candidates. Short-term programs may provide initial exposure to another culture, language, and school practices, while long-term programs may provide more challenging and in-depth professional experiences. Over 100 universities in the United States now provide some form of student teaching abroad (Reyes, Quezada, \& Alfaro, 2007). Studies of these programs have found that participants develop greater adaptability, awareness of self and others, and appreciation for multiple cultures and perspectives, among other gains (Cushner \& Mahon, 2002; Mahan \& Stachowski, 1990; Pence \& MacGillivray, 2008; Shiveley \& Misco, 2015). 
There seems to be international consensus that student teaching abroad confers significant benefits on pre-service teachers' professional skills and dispositions, including those involved in working with students from diverse cultural and linguistic backgrounds (Cwick \& Benton, 2009). However, most of the research has identified these benefits through survey or interview data collected immediately upon the participants' return. Few have studied participants' teaching in the following year to explore how the international experience has been translated to their domestic contexts in terms of their cultural awareness and skills in teaching diverse students (Lee, 2011; Martin, 2012; Willard-Holt, 2001). In a 2004 review of student teaching abroad programs, Quezada found that "there appears to be minimal research on the effects of student teaching abroad and its impact on teaching practices in the home country classroom" (2004, p. 463).

Given the limited nature of self-reported data, we decided to observe teachers in their home country classrooms in order to confirm or disconfirm their self-reported developments as a result of teaching abroad, as well as to identify practices that the teachers may not have even realized were likely influenced by their international experiences (see the case of Tabitha below for one example). We were also able to explore the ways in which the distinct characteristics of both the teachers and their new teaching positions influenced the ways they made meaning of their experiences abroad. The research questions guiding this study were:

1. How did student teaching abroad influence these participants' first-year teaching practices with culturally diverse students?

2. How were these impacts affected by the teachers' personal and professional backgrounds and current teaching contexts and situations?

\section{Context of the Program and the Host School}

In 2011, a large university in the southeastern United States inaugurated an annual program that would allow students in any of its teacher preparation programs to conduct four weeks of student teaching in Beijing, China. This would follow the completion of twelve weeks of local student teaching to fulfill state licensure requirements. Eighteen students elected to join the program, twelve of whom participated in our study. The students were required to attend nine biweekly preparatory sessions of Chinese language, culture, and education leading up to their departure in late March, 2012. These sessions included basic Chinese language lessons and discussions on Chinese traditional culture and religions, comparative studies in educational/social/political institutions and systems, and adaptive strategies for living, learning and working abroad (focusing on China).

Once in China, the students lived and worked Monday through Friday at a pre-K through $12^{\text {th }}$ grade private, international school serving primarily Chinese nationals. The secondary school, which is also a boarding school during the week, scheduled classes into the evening hours. The school offered Advanced Placement, International Baccalaureate, and SAT preparation courses for students wishing to attend universities in the U.S. or the U.K. Because admission to these universities typically requires the TOEFL exam, many of the American teachers were asked to focus their lessons on TOEFL preparation. Each student teacher was paired with a cooperating teacher in his or her content area(s), some of whom were non-Chinese teachers who had expatriated to China. Participant responsibilities in the classroom varied, but all independently led instruction for at least one or more weeks. Given that many of them were creating daily lesson plans and teaching into the 
evening, their only academic assignment during the trip was to keep a detailed blog. There were few excursions or other activities planned in the teachers' limited free time, but many of them spent weekends exploring Beijing and surrounding areas on their own. The school provided breakfast, lunch, and dinner to the American teachers in the cafeteria, so they would often converse with the year-round teachers (both Chinese and expatriates from other countries) during these meals. They also chaperoned field trips, co-planned school assembly programs, and generally felt relatively immersed in the life of the school.

\section{Theoretical Background}

Much of the research conducted on student teaching abroad has employed theories such as transformative learning theory (Taylor, 1994), perspective transformation (Hanvey, 1976), or intercultural/cross-cultural competency development to illuminate changes in the participants' personal and professional characteristics (Bennett, 2004; Cushner \& Mahon, 2002; Moseley, Reeder, \& Armstrong, 2008; Trilokekar \& Kukar, 2011). Researchers have made theoretical and practical connections between culturally responsive pedagogy and international educational experiences through the concept of an ethnorelative worldview, which can be developed through meaningful international experiences in other cultures (e.g., Bennett, 1993; Marx \& Moss, 2011; Quezada, 2004; Taylor, 1994). Bennett (1993) identified components of developing awareness of and sensitivity to cultural difference and organized these components into six stages (i.e., denial of difference, defense against difference, minimization of difference, acceptance of difference, adaptation to difference, and integration of difference), which indicate a process in terms of how ethnorelative views replace ethnocentric views. The first three stages are ethnocentric as one sees his own culture as central to reality. Moving up the scale, the individual develops a more sophisticated ethnorelative view and the individual may experience his or her own culture as in the context of other cultures.

Transformative learning theory posits that adults learn to live in a host culture by progressing through the phases of "setting the stage, cultural disequilibrium, nonreflective orientation, reflective orientation, behavioral learning strategies, and evolving intercultural identity" (Taylor, 1994, p. 160). Perspective consciousness (Hanvey, 1976), which was one of the first conceptualizations of the goals of global education, is the idea that to attain global awareness one needs an understanding that beliefs are not universally shared and that assumptions are shaped by unconscious influences. Although studies using these theories have significantly contributed to our knowledge of the impacts that overseas experiences have in terms of cross-cultural competency, they do not explain the differences in outcomes among various participants.

The social practice theory of identity (Holland, Lachicotte, Skinner, \& Cain, 1998) offers a lens for understanding these differences in participant outcomes. This theory helps reveal the complex and unique ways each participant self-authored the meaning of her experience abroad. The concept of authoring refers to how individuals construct their own identities through actively assigning meaning to events. One way they showed authorship, for instance, was through treating the trip as a tool to remind them how it felt to be a cultural outsider. Changes to their global competency (Banks, 2004) and culturally relevant teaching (Ladson-Billings, 2006), then, were actively produced through calling upon their memories of "disorienting experiences" (Trilokekar \& Kukar, 2011). This explains how a teacher's identity as a culturally relevant pedagogue, for example, is shaped potentially as much 
by her domestic contexts, such as administrative support and pressure to cover the standards, as by her previous experience in China, and the interaction of the two forces with each other.

Perhaps the most important element of Holland et al.'s (1998) theoretical model of identity for this study is the idea of semiotic mediation as a means to heuristic development of identity. The idea of semiotic mediation tools, which draws from the work of Lev Vygotsky (1930; as cited in Holland et al., 1998), posits that individuals impart meanings to objects or events that they can then use to modify their future behavior. For instance, teachers may actively use the memory of China to control and direct subsequent behaviors and attitudes, such as empathy. Thus, this lens attends to the ways in which the benefits of student teaching abroad are not passively received by participants, but rather are authored by the participants through their own agency. This helps to explain how the personal and professional backgrounds and teaching contexts of each participant may result in divergent meanings assigned to student teaching abroad.

\section{Literature Review}

There is a sizable body of literature on student teaching abroad, dating back to the early 1990 s (Lee, 2011; Mahan \& Stachowski, 1990; Pence \& MacGillivray, 2008; Phillion, Malewski, Sharma \& Wang, 2009). One of the earliest studies examined eight-week student teaching abroad programs in twelve different countries (Barnhart, 1989). The majority of these undergraduates taught in England, Switzerland, Venezuela or Germany. This quantitative study used survey data and found that most of the participants self-reported that they developed confidence, appreciation for other cultures, and global awareness. Most agreed with the statement that teachers should have international experiences. Other early studies also relied on quantitative methods (Mahan \& Stachowski, 1990). These studies, like several others on overseas student teaching (Phillion, Malewski, Sharma \& Wang, 2009; Willard-Holt, 2001), lacked an explicit theoretical framework.

Subsequent studies have used qualitative data to support the finding that teaching abroad may develop empathy, reflectivity, patience, sensitivity, and global competence in student teachers. Cushner and Mahon (2002) used open-ended questionnaires and journal reflections as their data sources. Trilokekar and Kukar (2011) used interview data collected after the participants' return. Moseley, Reeder, and Armstrong (2008) and Willard-Holt (2001) triangulated with methods such as focus groups and course assignments, as well as field notes of student teaching abroad observations. Among the smaller number of studies that have examined participants' teaching the following year to explore how the international experience has been translated to their domestic contexts, WillardHolt's (2001) study was based on a one-week international study-teaching tour, Lee's (2011) study was based on Hong Kong student teachers who taught in New Zealand, and Martin's (2012) study explored the impacts of student teaching overseas on first-year teaching. However, her data for student teaching overseas experiences was based on the participants' recollections in the interview during their first-year teaching (2012). Malewski and Phillion (2009) and Shiveley and Misco (2015) were some of the few researchers to track the long-term impacts of international teaching programs.

Shiveley and Misco (2015) used data from an online questionnaire completed by 148 students who had participated in a university's teaching abroad course over the prior 13 years and who were currently teaching or had taught since taking the course. The participants reported many ways in which the course influenced their teaching, some of which included: becoming more open-minded 
and reflective practitioners, gaining cross-cultural awareness and an interest in developing global citizenship and cultural awareness in their students, and developing a greater appreciation for student-centered planning and instruction. We did not find any studies that collected observational data and interview data in both host and home countries, or that paired follow-up interviews with classroom observations in the home country in order to corroborate participants' self-reported gains.

In addition, none of these studies discussed how participants varied from one another in the ways they made meaning of their experiences. A few did explore differences among participant outcomes; however, they focused on group-level, rather than individual, differences and only on factors related to contexts abroad rather than subsequent domestic contexts. For instance, Jiang and DeVillar (2011) compared teachers who student taught in affluent schools in Mexico and China with those who taught in a less affluent school in Belize. They found that those who went to Belize demonstrated more growth in adaptability, resourcefulness, and sensitivity to their students' backgrounds and needs, as a result of exposure to poverty and limited resources.

One study that did examine individual differences among the participants was conducted by Trilokekar and Kukar (2011). These researchers examined the "disorienting experience" of being in an unfamiliar culture as a catalyst for learning while student teaching abroad, specifically through "experiencing racial dynamics; experiencing outsider status; engaging in risk-taking/experiencing new identities; and recognizing privilege and power relations" (p. 1144). Among the five participants in this study, one of whom taught in Ireland and the rest in China, only one was a White female. The authors, then, were able to attribute some distinctions among the disorientation each experienced based on race, ethnicity, and language; however, the effects of variations in class and gender were not discussed. The study presented fascinating insights into the interplay of race and ethnicity with the lessons and meanings teachers identified from their trips. However, the specific effects of these lessons on the participants' subsequent teaching were not discussed.

One of the few studies that specifically explored race, gender, and social class on the various impacts of overseas student teaching was conducted by Malewski and Phillion (2008). They found that "the inversion of majority and minority status... and dissonance between pre-trip expectations and the realities of life in Honduras were referred to as the most profound learning outcomes" ( $p$. 57). They also found that encountering different gender roles led participants to think critically about the intersectionality (Crenshaw, 1991) of race and gender and whether their teaching styles favor one gender over another. This study demonstrated that the characteristics of participants affect their meaning-making while abroad; however, it examined only race, class, and gender, neglecting other potential personal and professional influences such as educational level, prior international experience, and grade level and content area taught abroad or in the home country.

Merryfield's (2000) study did not focus on study abroad, but did offer insights as to how global mindedness may develop differently for educators from dominant versus minority backgrounds. Merryfield studied 80 teacher educators who were recognized by their peers for their success in preparing teachers in both multicultural and global education by asking them to reflect upon the experiences that have most influenced their work in these fields. Among the important findings from her study, one suggests a significant qualitative difference between the identifying experiences 
of teachers of color and teachers of European descent. This difference was well summarized by Marx and Moss (2011) as double consciousness, i.e., American teachers of color may have had a consciousness of both their own primary culture as well as having experience of being an outsider who may encounter White privilege and societal racism. This may not be the case for middle-class White teachers who might have their most impactful experiences while living and teaching outside their own country. The White teachers found ways to practice culturally relevant pedagogy in U.S. schools by applying their overseas teaching experiences of being an outsider within another cultural context.

As each of these studies has built upon the insights of prior research, we are gaining a fuller picture of the factors that influence both the benefits and the drawbacks of student teaching abroad. However, Quezada (2004) pointed out that there has been little research that follows up with participants to determine how the knowledge, skills, and dispositions gained abroad transfer to their domestic teaching. Furthermore, we have much to learn about the specific influences on teachers' learning, such as background pedagogical preparation, prior international experience, and grade level and content taught following the trip.

The current study addresses three gaps in the literature on student teaching abroad: (a) the need for more nuanced understanding of influences other than race, class, and gender on how teachers make meaning of their international teaching experiences, (b) the need for more research that follows participants into their home country classrooms to investigate in what specific ways they demonstrate learning from their experiences, and (c) the current dearth of theorizing on how participants make meaning differently from one another in their first-year classrooms more than six months after the international student teaching internship.

\section{Methods}

\section{Research Design}

Qualitative case study methodology was used to gain an in-depth understanding of the complex ways in which participants applied their experiences to their subsequent teaching. The primary research design used a single case study methodology to examine a program (pre-service teacher teaching overseas) for a holistic inquiry into "a contemporary phenomenon with its real-life context" (Yin, 2009) in depth and over time. After the initial data collection and analysis, we felt the most interesting (but rarely studied) question might be how the first-year teachers with different personal and professional backgrounds applied the outcomes from their overseas student teaching experiences in different school contexts in their home country. Therefore, we decided to adopt Stake's (2006) multiple case study analysis for closely examining several cases linked together within a single research project. In this way, our multiple case study analysis did not repeat the findings from the single-case study, but built on them.

\section{Data Sources}

Table 1 indicates the primary stage of data collection: Steps 1-4 include collecting data from the twelve participants for pre- and post-trip surveys, structured journals, and observations and interviews in China. Survey questions were open and closed-ended and intended primarily to identify changes in knowledge and dispositions towards teaching culturally diverse students. Participants were asked to respond to online journal prompts at five points throughout the four weeks in China. 
These prompts asked them to identify insights gained about international education, as well as, new knowledge, skills, and dispositions of teaching culturally diverse learners in general and Chinese students specifically.

A later stage of data collection (Steps 5-6, see Table 1) included interviews and classroom observations with the five self-selected participant teachers in their domestic classrooms during the following year. Each of the five focal participants was observed once for at least one hour and then interviewed for approximately one hour directly after the observation, so that the participant could discuss elements of the particular lesson observed that incorporated the knowledge that they had gained from overseas experiences. Since we were especially interested in issues on which people disagree-complicated problems within complex situations - we posed a few open-ended questions to all interviewees, but we also prepared some questions particular to each participant (see Table 1 for a complete list of data collection procedures and instruments). Although field notes and survey data pertaining to the other seven participants are not explicitly mentioned in the results section, these data were coded and analyzed to inform our understanding of the five focal participants.

Table 1. Major Steps for Team Research Project

\begin{tabular}{l}
$\begin{array}{l}\text { Data Collection } \\
\text { Procedure and } \\
\text { Instruments }\end{array}$ \\
\hline
\end{tabular}

Pre-trip $\quad$ Jan 2012-March 2013
Preparation

Step 1

Step $2 \quad$ March 2012-April 2012

Step $3 \quad$ March 2012-April 2012

$\begin{array}{ll}\text { Step } 4 & \text { August 2012- December } \\ 2012\end{array}$

Step $5 \quad$ Summer of 2012
Design, revise and finalize survey instrument by research team Apply for university AA-IRB and received approval Bi-weekly China preparation classes for all participants who voluntarily enrolled in Student Teaching In China internship program

Administer questionnaire to research participants prior to their trip to China to visit and teach in Beijing. The questionnaire gathers data on pre-service teachers' prior cultural experiences and knowledge (travel, work abroad, family background, salient coursework, readings) as well as their initial perceptions and attitudes towards teaching in an ethnically and linguistically diverse classroom during their student teaching internship that they completed prior to the trip.

Research participants write in a journal (and blog if desired) their reflections, impressions, and experiences periodically throughout their time in China. Copies of the journal entries are used to trace participants' changes throughout their time abroad.

One of the researchers goes with student teachers to China. Researcher observes, informally interviews, and takes field notes in China.

Administer questionnaire to research participants after their return from China to learn in what ways their experiences there impacted their attitudes, perceptions, and understandings of China and working with diverse learners in general. 
Step 6

Oct 2012-Novermber 2012

Oct 2013- July 2013

Observe participants teaching and collect ethnographic observations during classroom visit during the participants' first year of teaching.

Multiple case study analysis: Audio record and transcribe individual interviews with each of the five participants during their first year of teaching to learn more about whether the trip to China has impacted their strategies and practices in the classroom and if so, in what ways it has impacted their practices. Triangulate the data from journals, surveys, and post-observation interviews within each case and also across the cases to reveal the complexity and the situationality of the cases.

\section{Participants}

Of the twelve voluntary participants who completed at least some portion of the data collection methods, only five agreed to be interviewed and observed in their post-China domestic teaching positions. ${ }^{1}$ However, we did use the journal and survey responses from all the participants to gain a fuller understanding of the knowledge and dispositions gained abroad. The five who agreed to be observed were all White, middle-class females ranging in ages from 22 to 40 (see Table 2 for detailed characteristics of each participant). The researchers obtained approval from the Institutional Review Board (IRB) before beginning the study, and implemented approved procedures as stipulated. Informed consent was obtained from each participant, and all participants were given pseudonyms to protect their anonymity.

Table 2. Characteristics of Participants

\begin{tabular}{lllllll}
\hline Participant & Gender & Race & Age & Program Area & Currently teaching & $\begin{array}{l}\text { Experience teaching/ } \\
\text { studying abroad }\end{array}$ \\
\hline Lilly & F & W & $20-25$ & $\begin{array}{l}\text { Undergraduate } \\
\text { Elementary }\end{array}$ & $5^{\text {th }}$ grade & none \\
Sadie & F & W & $20-25$ & $\begin{array}{l}\text { M.A.T. } \\
\text { ESL }\end{array}$ & Elementary ESL & $\begin{array}{l}\text { studied in Germany and } \\
\text { the UK for 1 semester } \\
\text { each }\end{array}$ \\
Mindy & F & W & $40-45$ & $\begin{array}{l}\text { M.A.T. } \\
\text { Social Studies } \\
\text { M.A.T. }\end{array}$ & $\begin{array}{l}\text { Middle School Social } \\
\text { Studies }\end{array}$ & none \\
Tabitha & F & W & $20-25$ & $\begin{array}{l}\text { High School Math } \\
\text { Child Development and } \\
\text { Family Studies }\end{array}$ & Preschool in Germany for 3 \\
madeleine & F & W & $30-35$ & $\begin{array}{l}\text { month } \\
\text { none }\end{array}$ \\
\hline
\end{tabular}

\section{Data Analysis}

We conducted several stages of data analysis as it became clear that the most interesting discoveries were not thematically distributed, as we had expected, but rather emerged from within each of the five cases. The multiple case study analysis method was summarized into three different analysis tracks based on depth of analysis: we adopted the track of Type I analysis that emphasizes case findings, thereby preserving situationality, which can be obscured by merely emphasizing the

1 The participation was self-selected. The trip was not required by the university, and each student had to pay two thousand dollars to offset the travel costs. There is the possibility that students who chose to go to China were likely to have been more interested in intercultural activities than those who did not go. For multiple case study analysis, this approach is acceptable as Stake (2006) stated that sometimes the cases are selected for us; sometimes we choose them. 
comparison (Barela, 2007). For instance, in the first stage of coding, we identified and coded themes such as "dispelled myth of model minority" and "reinforced U.S. teacher preparation coursework." However, in comparing these findings with the literature on student teaching abroad, we determined that highlighting these would support previous research but not contribute new knowledge to the field.

More enlightening were the ways in which participants differed, and the evidence for why they might have differed, i.e., understand better how the "whole" (the main phenomenon that Stake also calls as a "quintain") operate in different situations. Thus we undertook a second round of analysis with this in mind. Codes that emerged during this round included "confirmation of second language acquisition theories" (Sadie) and "language strategies with pre-verbal children" (Madeleine). We decided to use multiple case study analysis: in the context of the larger research project, the data were analyzed and reported for each of the five cases, hence we had five different stories to tell in our findings section. By triangulating the data from journals, surveys, and post-observation interviews within each case and also across the cases, we were able to ensure greater rigor, breadth, and complexity without diminishing the situationality of the cases (Barela, 2007; Denzin \& Lincoln, 2011). In other words, readers will be given the opportunity to know how the study of various issues that cut across cases contributes to understanding the quintain, the main phenomenon.

\section{The Roles of the Researchers}

To triangulate the data, the principal researcher took the role of a participant observer throughout the preparatory sessions and for two weeks of the time the participants spent in China. She stayed in the same apartment building as the participants and observed several participants in their classrooms in China. She took extensive field notes on her observations and had informal conversations with participants. In this way, the "knower and respondent cocreate concrete understandings" (Denzin \& Lincoln, 2011, p. 24). The other researchers collaborated by designing and revising survey instruments, collecting survey data, conducting post-trip surveys, analyzing the data, and writing and revising the paper. All researchers had public school teaching experience, taught teacher education classes at the college level, had significant international cultural experiences, and were bi-lingual or multi-lingual. Each researcher independently analyzed the data and then compared the codes that emerged, ultimately collapsing codes until agreement was met. Authenticity, trustworthiness, and transferability were addressed through the triangulation of data from multiple sources, thick quotes and description (Geertz, 2000), and comparison of data interpretation by multiple researchers.

\section{Results}

To highlight the differences among the participants' identities in practice, a result of their varied background experiences and their current teaching positions, the results are divided individually by participant. Thematic similarities and differences among the group are included in the discussion. Each subheading includes an epithet for the participant, not to be reductive but for easier recognition when making cross-case comparisons in the discussion. We include extensive quotes in keeping with Eisner's (1991) contention that greater highlighting of teacher voices through qualitative research is needed. 


\section{Lilly-the First-time Traveler}

Prior to this trip, Lilly had never been out of the country and had had minimal interaction with, or perhaps more importantly, little awareness of immigrants in the U.S. In her pre-trip survey she wrote, "I probably interact with immigrants in my life, but I don't really know where because I don't know if people are immigrants." In her local student teaching prior to the trip, she did have immigrant children from China and Iran in her classroom, so she was able to answer survey questions aimed at her opinions toward immigrant students. She indicated on the survey that she found immigrant students to be more attentive, motivated and well behaved than non-immigrant students. However, she also believed they were "reluctant to communicate with peers, especially about their own experiences" and had lower attendance, "due to celebration of holidays not recognized as holidays in the United States" (pre-trip survey). She added, "but I don't think this applies to all immigrants. Some would go to school no matter what" (pre-trip survey).

Overall, she demonstrated an additive (Gibson, 1995), culturally relevant (Ladson-Billings, 2006), albeit simplistically, perhaps owing to her lack of experience, writing that immigrants should maintain their heritage languages and not be forced to assimilate, but rather "adapt at their own rate and the adaptations will be more authentic and allow the child to express his/her personality." However, given the choices on the pre-trip written survey, she fell short of believing schools should facilitate the maintenance of heritage language, instead remarking that schools should "remind them the value of maintaining heritage languages."

In addition to her lack of interactions with immigrants, Lilly was the only participant among the five without previous international experience. Therefore, it is no surprise that the trip seemed to have the strongest impact on her intercultural sensitivity (Bennett, 2004). Following her student teaching in China, Lilly took a position as a fifth grade classroom teacher in an average-sized, rural elementary school with a very small immigrant population. Seated in her classroom, she reflected on the importance of the trip for her development and how her recollection of feeling like a cultural outsider in China has made her more sensitive to English language learners:

Immersing myself in a new culture was the most important part because it really made me think about what it would be like to be a student who was not speaking English as their first language ...... How to ride the subway—all these things were new to me, just putting myself in the shoes of a student who is an English language learner. . Having interactions with different people gave me a new appreciation for just respecting other people and their differences so I am very much aware of that and I try to include that in a lot of things we do. (Interview, November 15, 2012)

In the final sentence, she recognized the impact that this newfound respect for differences has specifically on her teaching. For example, she explained how she incorporated non-dominant voices in her curriculum and encouraged her students to think critically about the re-telling of history. Her fifth grade students read excerpts of Zinn's (1980) A People's History of the United States to gain Native American perspectives on Columbus's discovery. She continued,

And then after that we read what the textbooks had to say, and the students were in complete shock that the textbook had left out what he [Columbus] really did with the Native Americans. (Interview, November 15, 2012) 
However, the difficulty of translating beliefs into practice and the contradictory nature of some of her practices were revealed when she was asked whether she felt more prepared to teach in a culturally responsive way following the trip. She described how she would remind students that, while in China, "[She] didn't speak any Chinese and... was able to communicate with people without talking." Here the China trip served as a semiotic mediation device as Lilly recalled how limited she felt not being able to communicate. While this example was reduced to the purpose of classroom management, rather than student learning, it showed her internalization of her experiences in China and its impact on practice.

An additional example echoed Lily's difficulty translating her newly formed beliefs about the value of culturally responsive pedagogy into classroom practices. She offered an example that she argued required her students to draw from multiple perspectives. However, the example, which was a discussion of why people might vote for Mitt Romney or Barack Obama in the upcoming November 2012 presidential election, focused solely on general American perspectives. This was unlikely to resonate with immigrant students or create space for the development of intercultural competence in non-immigrant students.

While her examples from practice demonstrated limited knowledge about how to translate culturally relevant teaching into classroom practices, Lilly did express many areas of growth in her personal intercultural competence stemming from her trip to China, including adjustment of her expectations to allow for cultural differences (such as a reluctance to volunteer orally) and understanding that immigrant parents may be reluctant to speak to her but that, "no matter where you are, parents care about their children and they want their children to do well" (Interview, November 15, 2012). Thus Lilly's lack of prior international experience may have allowed more room for growth, even if her ultimate intercultural competence was relatively less developed than that of the other participants.

\section{Sadie_the ESL Teacher, Frustrated by New Language}

Sadie had previously studied abroad in Germany and England and rated herself fairly proficient in German and Spanish. She was completing her Masters of Arts in Teaching (M.A.T.) degree in English as a Second Language (ESL) and therefore had much more knowledge about immigrant students and how to accommodate instruction compared with the other student teachers. Thus one may expect the trip to have had relatively less of an impact on her. However, we found that her reflectiveness and strong emotional responses, especially in terms of language and cultural barriers, suggested that it was just as influential on her practice. In fact, it may be precisely because of her dedication to working with immigrant students that Sadie, unlike the other participants, saw her experiences in China as a semiotic mediation device (Holland et al., 1998) and did so even while she was in China.

Before the trip, Sadie was already committed to maintaining the heritage languages of her students and felt she had a strong knowledge of culturally relevant pedagogy (Ladson-Billings, 2006). However, she said the trip reinforced these dispositions and allowed her to see this theory in practice. For example, the trip reinforced her belief that home languages should be welcomed at school because she could identify with the frustration of not being fully fluent in a language. Sadie explained, "if anything, I value it more because I was glad to see my friends at lunch and I could just 
use slang, and I could be sarcastic and they got it" (Interview, October 25, 2012). The experience of living among speakers of a language she did not know also convinced her of the validity of second language acquisition theories she had learned in her teacher preparation coursework. She recalled learning the theories of linguist Stephen Krashen, but said she fully believed his argument about the natural learning of language only when she realized she was picking up on tones and sentence structure through her immersion experience in China.

Sadie taught a class of 35 tenth graders in China. This experience reinforced her commitment to culturally relevant pedagogy and allowed her to see this theory in practice. She reported that,

In China if something wasn't culturally relevant to [the students] they did not understand it. I saw how much more effective it was when I made an effort to relate to them and ... so it sort of really clicked because I like had, had, had to do it. (Interview, October 25, 2012)

In addition to the particularities of Sadie's education coursework and commitment to immigrant students, she expressed much greater frustration while living in China than any other participant. She was particularly exasperated by her inability to read or even recognize any characters in Chinese. She said that the experience of "exhaustion" listening to Chinese all day culminated one afternoon:

I was just mad. I went back to my flat and I said I do not want to hear any more Chinese. If anyone speaks Chinese to me I think I might yell at them ... I thought, OK, when I have first and second graders who are poking their neighbors and not paying attention and rolling around on the carpet it's probably because they're mad because they don't know what's going on. (Interview, October 25, 2012)

She added that the trip's location in China was significant because, unlike in Germany or a Spanish-speaking country, she was extremely frustrated by not being able to read or even recognize any characters. In the blog she kept while in China, Sadie wrote,

I am getting only a small taste of what my future students will go through in adjusting to a new place. I cannot imagine moving here and having to learn the language. It would take years to have a conversation, much less read fluently or write. I am learning to be patient with my own frustrations, which will in turn translate into patience with my future students. I cannot tell you how glad I will be to return to a place where I can READ. . . We've all been saying that we really jumped off the cultural deep-end by coming here. (Blog entry, April 22, 2012)

Of significance in both passages was Sadie's filtering of her experiences as a non-Chinese speaker in China through interpretations of how these would shape her identity as a teacher. Perhaps Sadie constructed her trip as a semiotic mediation device more than the other participants because this provided a way to cope with her frustrations in China.

Back at home it is clear that her experience in China has shaped her classroom practices. She reported that she goes to great lengths to ensure that her students succeed in the classroom by planning for multiple levels of differentiation for a learning task. For example, 
I have become very intentional about thinking about where those blocks [of communication] might happen, where it might get stuck. It'll probably be fine but it's possible that this won't work, or I assume these kids know this but if they don't here's you know a level below it or another way to come at it. (Interview, October 25, 2012)

The day that we observed Sadie teaching a math lesson to two immigrant students from India and Korea, she led them through a hands-on activity in which they created patterns with blocks. She had also prepared two additional activities that were less complex. Sadie demonstrated the direct impact of student teaching abroad in China on her practice by anticipating the needs and potential confusion of her immigrant students.

\section{Mindy-Empathetic but Limited by School Conditions}

Mindy was in her early 40s, had two elementary age children, and had previously worked as the marketing director for an immersion Chinese preschool. Like Sadie, Mindy was in the process of completing her M.A.T. in secondary social studies. Prior to the trip she felt that, between her education classes, her natural disposition, and her prior interaction with immigrants through her marketing job, she was already prepared to teach in a culturally responsive way. Still, it appeared that the trip served as a semiotic mediation tool (Holland et al., 1998) and further solidified her commitment to cultural responsive teaching as a high priority for her:

I think about [teaching] differently. . . When I do my lesson planning it's always at the forefront of my mind that I need to take that next step and make sure my lessons are focused towards English language learners or people from multicultural backgrounds. But I don't think the methodology itself is anything new, but I'm just more aware of it. (Interview, October 23, 2012)

Despite her intentions to the contrary, the most significant factors at play in Mindy's ability to teach in a culturally responsive way were the conditions she encountered upon her return from China as a social studies teacher in an overcrowded, low-income middle school with high teacher turnover and student suspensions. In her interview she stated,

I feel somewhat ill-equipped in this classroom sometimes because there are students who have a really hard time understanding what we're doing in social studies and there's nobody in here to help them when I've got all these other kids in the class, you know, and a lot of classroom management issues I'm dealing with and to get that time to get over there and to help students. . . I think more could be done. (Interview, October 23, 2012)

She lamented that the school district does not provide ESL specialists in social studies classrooms: "it's unfortunate because there's a lot of reading in social studies." She tried to overcome this by having fluent bilinguals translate for newcomers but said, "There are some classes where the students that can translate . . . don't understand what's going on because they're not paying attention" (Interview, October 23, 2012). This was exacerbated by the school's policy of "math and English [testing] dictating how the rest of the schedule goes" so that "the ELLs [English Language Learners] are grouped in with students who are maybe low-performing groups." Thus, although the trip strengthened Mindy's commitment to supporting immigrants, her novice teacher status and school and district realities severely limited her ability to do so and tested her resolve to shape her practice around the needs of ELLs. 


\section{Tabitha-the Math Teacher}

The influence of the China trip on Tabitha was tempered by a higher baseline of intercultural experiences combined with what she perceived as limited opportunity for multiple cultural perspectives in the math curriculum. Tabitha, an M.A.T. graduate in secondary math, had studied in Germany, traveled to Honduras, spoke some Spanish and had friends who were Honduran immigrants. Her responses to the pre-trip survey open-ended questions illustrated that she valued the maintenance of heritage cultures and recognized that "limited English ability does not respond to limited intellectual ability." Perhaps one result of her greater familiarity with cross-cultural learning was a hesitancy to make generalizations about immigrant students. She qualified many of her pre- and post-trip survey responses with "it depends on the student."

This higher baseline of intercultural awareness may have limited Tabitha's growth to some extent; however, she did say that the trip "made me more sensitive to differences because I was a fish out of water in China" (Interview, December 17, 2012). She also gained new insights into the social struggles of immigrants through conversations with Chinese students about their concerns regarding fitting in at American universities. This made her realize her current students may share this concern, "which was not something that had crossed [her] mind before the trip" (Interview, December 17, 2012).

The greater constraint on the salience of the trip as a semiotic mediator was her struggle to find opportunities to bring multiple cultural perspectives into a math class. She wrote in her post-trip survey, "I have difficulty finding ways to incorporate social justice issues into the math curriculum," and, when asked in her interview how she incorporates diverse cultures, she answered, "That's something that I have to work on more." However, observations of her teaching revealed many ways she supported immigrant students perhaps without realizing it, such as using visuals and realia, assessment modifications, and having a bilingual student with strong math skills tutor struggling students (Observation, December 17, 2012). Although these decisions may not necessarily be attributable to her experiences in China, it is likely that teaching classes of entirely English learners in Beijing improved her ability to intuit effective supports such as these.

\section{Madeleine-the Teacher of One Year-olds}

One might expect that teaching one-year old children would offer few opportunities to demonstrate culturally relevant pedagogy or the valuing of multiple perspectives. However, Madeleine, a nontraditional undergraduate (in her early thirties) in Early Childhood and Family Studies, found interesting ways to make her trip to China relevant to her current context of work with young children. For instance, she stated,

Working in China and not being able to understand what the children were saying and having to look at other ways of communicating ... you're not always going to understand what the kids want and how to work with that. (Interview, November 8, 2012)

One recurrent theme in Madeleine's interview was how the trip deepened her understanding of cultural differences among families, which she viewed as particularly important because, "with this age group, it is so much more important to build the relationships with the parents because the kids can't tell you if they didn't sleep well the night before or if they're hungry" (Interview, November 8, 2012). Another benefit she identified was that, after exposure to cultural differences (such as how 
one boards a bus), "it helps me then you know to look at the little things that I encounter here that may, if I step back and think about it, I can figure out where it might be coming from" (Interview, November 8, 2012). In this case, the student teaching element of the trip played less of a role than the element of immersion in another culture; however, she did comment that the knowledge she acquired about different preschool models in China was also beneficial. The Chinese school had one Montessori classroom, one traditional Chinese classroom, and one classroom intended to reflect international influences. Madeleine commented that she appreciated being able to try different things and "pull out the different things that you like" (Interview, November 8, 2012).

\section{Discussion}

Prior studies of teaching abroad have suggested that such experiences may enhance teachers' ethnorelative worldviews (Cushner \& Mahon, 2002; Moseley, Reeder, \& Armstrong, 2008; Trilokekar \& Kukar, 2011). Our study did find some evidence of this; however, we discovered that these were not the most distinctive findings that emerged. More distinctive were the individual departures from the stage models (e.g., Bennett, 1993; Taylor, 1994) of cultural competence development. Furthermore, some of the participants spoke about how their coursework had already given them a foundation in culturally relevant pedagogy, and therefore, they did not identify their experience in China as having significantly contributed to their commitment or their ability to be culturally relevant. We sought to understand why it was that our participants did not express a transformation or a redoubling of their commitment to culturally relevant pedagogy, as we had expected. In this section we describe the similarities and differences in experience and impact of student teaching abroad on the five focal student teachers. We argue that many factors, including the on-going negotiation of identity especially of young professionals entering or re-entering the teaching profession, impact the effects of overseas experiences on their teaching practices.

"We really jumped off the cultural deep end by coming here," Sadie mused in her interview. The student teaching abroad experience deeply challenged each of the five participants to take a second look at their own perceptions of and expectations for the classroom. Each teacher expressed some improvement in or greater commitment to adapting instruction for culturally diverse students, but the degree of change varied with the participant's personal experience, academic and professional backgrounds, and current teaching area and school context. Whereas previous study abroad literature has viewed these changes as stages of growth toward greater intercultural competence (Cushner \& Mahon, 2002), we viewed their behavior as "a sign of self in practice, not as a sign of self in essence" (Holland et al., 1998, p. 31). In other words, China did not fundamentally change who each teacher was, but it did serve as a semiotic mediation tool with which each one reminded herself how difficult it was to be a foreigner in China, and therefore how important it is to accommodate her immigrant students. Their international experiences continued to serve as an address to which they must respond (Holland et al., 1998). And therefore, their responses were constructed through forming and re-forming the identity of a culturally relevant pedagogue. Each purposively used this remembered story to "cast oneself as a new actor in a new social play" (p. 281).

Lilly, for instance, used her memories of being a cultural and linguistic outsider (Merryfield, 2000) as a semiotic mediation tool to reinforce her appreciation for perspectives and characteristics different from her own. Applying this to practice, she placed greater emphasis on teaching about 
multiple perspectives and questioning the dominant perspective. However, she did not demonstrate or cite any examples of incorporating global perspectives or the personal knowledge she gained through travel in China. Regarding the latter, her evocation of being the linguistic outsider was used only to remind students that they need not to talk to communicate. As a first-time traveler, Lilly, perhaps unsurprisingly, did not reach the same depth of global awareness or double consciousness (Marx \& Moss, 2011) as some of the more experienced travelers.

Sadie's experiences as a Master's student in teaching ESL, on the other hand, was one in which she already valued multiple languages and perspectives. More significant for her use of the trip as a semiotic mediation tool was her intense frustration with her inability to understand or read Mandarin. She was the only participant to express such exasperation, but she seemed to use this distress as a mediation tool while in China to influence her future instructional decisions. For instance, while noticing the struggles of her Chinese students, she anticipated similar struggles and behaviors in her future students. Her frustration while in China served as a constant reminder to empathize with Chinese students learning English as well as future ESL students in her home country.

We expected to find little evidence of the professional impact of the trip on Madeleine, the teacher of one year-olds; however, she authored a meaning to the trip for her own purposes. She explained that teaching abroad contributed to her cultural competency with parents and to being able to understand the children's needs without the aid of language.

Tabitha was the most reluctant to claim she had improved her ability to teach immigrant students, and she avoided making generalizations about immigrant students, which indicates some degree of cross-cultural competency. For instance, she answered three survey questions on her perceptions of immigrant students with "It depends on the student." Tabitha's prior international travel and friendship with foreign-born peers likely contributed to this reluctance to assign meaning beyond individual differences. In each case, the teacher's identity and experiences in China interacted with her new context to shape the way each authored the relevance of her trip to her current pedagogy.

Because identities are constantly negotiated and formed in social practice with others, each teacher authored the meaning of her experience differently (Holland et al., 1998). In the new context of first-year teaching, identities were constantly being formed and re-formed, contested, and co-constructed. Each cast herself as someone who has had the disorienting experience (Trilokekar \& Kukar, 2011) of not understanding the language and culture of her surroundings and therefore can now better understand what her newcomer students may be feeling (Merryfield, 2000). In this way, they used their agency to author the meaning of their experiences in China for their future teaching.

\section{Implications}

The findings suggest that all teachers can benefit from international student teaching; thus, educational institutions should provide international opportunities and encourage students to take advantage of them. However, based on what we have learned from this year-long study, colleges and universities can re-plan their overseas teaching programs to make them more meaningful and useful for novice teachers. How to improve the program will vary according to many factors, some of which are controllable, and we propose the following suggestions. 
First, we believe that the ability to draw connections from experiences abroad to the current teaching context can be enhanced through multiple placements ${ }^{2}$ and guided reflections, which will be constructed differently for student teachers who will have positions in different subjects, grade levels, and types of schools. For instance, Madeleine indicated that one benefit of her time in China was the opportunity to try three different instructional models for pre-K: Montessori classroom, traditional Chinese classroom, and a classroom intended to reflect international influences. She reported that she could extract components from all three approaches to use in U.S. pre-school classrooms. The story of Tabitha, the math teacher, can serve as another example for guided reflection. She developed multiple ways inside and outside the classroom to support the math learning of culturally diverse students, even when she might not have realized it.

Second, it is important that programs follow up with study abroad participants in their future teaching to monitor and facilitate their ability to relate the experience to their current professional activities. The repeated use of the experience as a continual reminder to be empathetic and supportive may eventually "be internalized" as the "process of self-training may even be forgotten and the evocation of control may become automatic" (Holland et al., 1998, p. 37). As Martin and Griffiths (2014) concluded in their study on the transformative learning of teaching abroad, "the experience itself is not enough - spaces for dialogue and critical reflection on experiences are also necessary" (p. 953). Thus we recommend that, during their first years of teaching, participants be invited back to their educational institutions to present their experiences to the next group of students traveling abroad. If distance is prohibitive, participants could use webbased communication, or write written reflections to be shared with prospective participants.

The other factors that influenced the meanings participants assigned to the trip are less controllable; however, they can still be accommodated so that participants benefit as much as possible. Participants with fewer prior international experiences or more ethnocentric worldviews could benefit from more extensive pre-trip intercultural competency training and post-trip structured reflections with feedback as needed to broaden their perspectives. For instance, Lilly could benefit from constructive feedback on her use of the China example to silence her students and of the presidential election lesson as an example of multiple viewpoints. These viewpoints were still solely focusing on U.S. culture and thus did not reflect the global awareness the trip was intended to foster. Similar studies have found that, despite intentions, international experiences can sometimes reinforce stereotypes and foster paternalistic thinking (Martin \& Griffiths, 2014; Stein et al., 2016). Thus coordinators should raise participants' awareness of these risks and guide critical reflection on their assumptions.

Another factor that mitigated culturally responsive teaching was working in a school with discipline struggles, as in Mindy's case. Although this is another factor that cannot be controlled, programs could provide follow-up support with teachers like Mindy to assist them in applying abroad experiences even while navigating challenging school environments. If this is costprohibitive, even a one-hour interview session with a researcher, such as our session with Mindy,

\footnotetext{
${ }^{2}$ Zhao, Meyers, and Meyers (2009) suggested a two-placement overseas student teaching experience may also help student teachers make comparative reflections between these two placements.
} 
allows the teacher the time and opportunity to pause from daily demands to remember the overseas experience and the insights that she had gained, which had perhaps been temporarily pushed aside.

Similarly, teachers like Tabitha, who may struggle to identify ways to incorporate multiple cultural perspectives into a content area such as math, could be assisted through follow-up support or interviews. Tabitha already provided supports to her immigrant students without even realizing it in some cases. By drawing her attention to these actions during the interview, Tabitha would perhaps be more likely to repeat these accommodations in the future and implement them more purposefully. Pence and Macgillivray (2008) suggested having trip participants as guest speakers for the group traveling the following year. This would provide another opportunity for them to author the meanings of their trip and articulate them to others.

A final implication for student teaching abroad program coordinators is that these findings should shape the content of preparatory sessions for all participants. Many have emphasized the importance of requiring teachers to attend a course or other training experience before travelling abroad (Pence \& Macgillivray, 2008; Quezada, 2004), but few have specified what the content of these sessions should be. Just as researchers should take into account differences in participants' race, gender, class, and background experiences, so too should the leaders of preparatory sessions. They should make clear to students that these differences may affect the meanings that they make of their international teaching both while abroad and in their future domestic teaching. They can provide strategies to students for assigning meaning and for later use of these as semiotic mediation tools.

Another important consideration for program coordinators, which has been underscored in literature on the postcolonial contexts and one-sided nature of many study abroad programs, (e.g., Martin \& Griffiths, 2014; Stein et al., 2016), is how such programs may privilege dominant Western values and ignore the desires and needs of the host communities. Participants in this study were not asked to interrogate "how their own positions within the highly uneven and racialized global political economy contribute to the very harm they have supposedly travelled abroad to address" (Stein et al., 2016, p. 9). Prior to and during engagements with host communities, teachers should reflect on who benefits from these exchanges and how this reinforces global hierarchies. They should also take care not to reduce all students from other cultures into a general category of 'Other' (Martin \& Griffiths, 2014, p. 942). Likewise, teachers should question any expectation that learning in one particular foreign site will garner insights about students from other global locales.

\section{Limitations}

We acknowledge several limitations to the current study including 1) self-selection of participants due to the cost of the trip (discussed in the Methods section); 2) lack of pre-trip observations of student teachers in their domestic placements; and 3) the homogeneity in participants in terms of gender, sexual orientation, and class.

First, the researchers did not conduct pre-trip observations or interviews. Therefore, we relied upon pre-trip surveys that asked student teachers to rate themselves on skills and dispositions prior to the trip to China. More robust data would have been provided through observations in their 
domestic placements conducted prior to student teachers' departure to help tease out changes in pedagogy attributable to student teaching abroad.

Having only five participants, all of whom were White, middle-class, heterosexual females, limited the transferability of the findings to other populations of teachers. However, this homogeneity did allow the data analysis to highlight the significance of other differences, such as content area and prior international experience. Future research should explore other differentiating characteristics, such as age, activities during student teaching abroad, and opportunities for post-trip reflections, to name a few examples, and how these influence the meaning of teaching abroad.

\section{Conclusion}

This study addressed a gap in previous student teaching abroad literature, which has rarely followed participants into their teaching in their home country. We found that, despite differences in the grade level and content area taught in their first year, all participants reported and demonstrated pedagogical growth as a result of their experiences abroad. Furthermore, we found that these differences, as well as variations in each teacher's personality and prior international experience, led each participant to assign a unique meaning to the trip. Therefore, we should expect international teaching experiences to foster growth in varied ways depending upon the participant and their subsequent teaching contexts.

Common among all was a use of the trip as a semiotic mediation tool to remind them how difficult it can be for a linguistic and cultural outsider and to motivate them to make extra efforts to support their immigrant students. However, given the intensity of first-year teaching, participants needed to carve out time to reflect on the relevance of China to their current teaching. Therefore, the main recommendation of this study is for student teaching abroad programs to structure opportunities for guided reflection during the participants' subsequent teaching in the United States. Future research should explore how to structure these reflections to make them most effective, which would need to take into account variations among content areas and grade levels taught, as well as personal characteristics. In doing so, teachers can adjust their authorship to the contexts of their future teaching and to the unique needs and personalities of the students in their classrooms.

\section{References}

Banks, J. (2004). Teaching for social justice, diversity, and citizenship in a global world. The Educational Forum, 68, 296-305.

Barela, E. (2007). Book Review: Multiple Case Study Analysis, by Robert E. Stake. American Journal of Evaluation 28, 570-572.

Barnhart, R. S. (1989). The assessment of growth resulting from a student teaching experience in an international setting. International Education, 18, 5-13.

Bennett, M. J. (1993). Towards ethnorelativism: A developmental model of intercultural sensitivity. In M. Paige (Ed.), Education for intercultural experience (pp. 21-27). Boston, MA: Intercultural Press.

Bennett, M. J. (2004). Becoming interculturally competent. In J. Wurzel (Ed.), Toward multiculturalism: A reader in Multicultural education (pp. 62-77). Newton, MA: Intercultural Resource Corporation.

Crenshaw, K. W. (1991). Mapping the margins: Intersectionality, identity politics, and violence against women of color. Stanford Law Review, 43(6), 1241-1299.

Cushner, K., \& Mahon, J. (2002). Overseas student teaching: Affecting personal, professional and global competencies in an age of globalization. Journal of Studies in International Education, 6, 44-58. 
Cwick, S., \& Benton, J. (2009). Teacher preparation programs: Making student teaching abroad an effective option. Delta Kappa Gamma Bulletin, 75(3), 37-42.

Denzin, N. K., \& Lincoln, Y. S. (Eds.). (2011). The SAGE handbook of qualitative research. Thousand Oaks, CA: Sage.

Eisner, E. W. (1991). The enlightened eye: Qualitative inquiry and the enhancement of educational practice. New York, NY: Merrill.

Geertz, C. (2000). The interpretation of cultures: selected essays (2000 ed.). New York, NY: Basic Books.

Gibson, M. A. (1995). Additive acculturation as a strategy for school improvement. In R. G. Rumbaut, \& W. A. Cornelius (Eds.), California's immigrant children: Theory research, and implications for educational policy (pp. 77-105). San Diego, CA: Center for US-Mexican Studies.

Hanvey, R. G. (1976). An attainable global perspective. New York, NY: Center for Global Perspectives in Education.

Holland, D., Lachicotte, W., Skinner, D., \& Cain, C. (1998). Identity and agency in cultural worlds. Cambridge, MA: Harvard University Press.

Hollins, E. R., \& Guzman, M. T. (2005). Research on preparing teachers for diverse populations. Studying teacher education: The report of the AERA panel on research and teacher education, 477-548.

Jiang, B., \& DeVillar, R. A. (2011). Effects of school and cultural contexts on student teaching abroad outcomes: Insights from U.S. student teachers in Belize, China, and Mexico. Action in Teacher Education, 33, 47-62.

Ladson-Billings, G. J. (1995). Toward a theory of culturally relevant pedagogy. American Education Research Journal, 35, 465-491.

Ladson-Billings, G. (2006). Yes, but how do we do it? In J. Landsman \& C. W. Lewis (Eds.), White teachers/diverse classrooms: A guide to building inclusive schools, promoting high expectations, and eliminating racism (pp. 29-42). Sterling, VA: Stylus.

Lee, J. F. K. (2011). International field experience - What do student teachers learn? Australian Journal of Teacher Education, 36(1), 1-22.

Mahan, J. M., \& Stachowski, L. (1990). New Horizons. Student teaching abroad to enrich understanding of diversity. Action in Teacher Education, 7(3), 13-21.

Malewski, E., \& Phillion, J. (2009). International field experiences: The impact of class, gender and race on the perceptions and experiences of preservice teachers. Teaching and Teacher Education, 25, 5260.

Martin, L. C. (2012). International student teaching in non-Western cultures: Impact on first year teachers. Unpublished dissertation. Iowa State University, Ames, IA.

Martin, F., \& Griffiths, H. (2014). Relating to the 'Other': Transformative, intercultural learning in postcolonial contexts. Compare: A Journal of Comparative and International Education, 44(6), 938-959.

Marx, H., \& Moss, D. (2011). Please mind the culture gap: Intercultural development during a teacher education study abroad program. Journal of Teacher Education, 62(1), 35-47.

Merryfield, M. M. (2000). Why aren't teachers being prepared to teach for diversity, equity, and global interconnectedness? A study of lived experiences in the making of multicultural and global educators. Teaching and Teacher Education, 16(4), 429-443.

Mosely, C., Reeder, S., \& Armstrong, N. (2008). "I don't eat white": The transformational nature of student teaching abroad. Curriculum and Teaching Dialogue, 10, 55-71.

Pence, H. M., \& Macgillivray, I. K. (2008). The impact of an international field experience on preservice teachers. Teaching and Teacher Education, 24(1), 14-25.

Phillion, J., Malewski, E. L., Sharma, S., \& Wang, Y. (2009). Reimagining the curriculum: future teachers and study abroad. Frontiers: The Interdisciplinary Journal of Study Abroad, 18, 323-339.

Quezada, R. L. (2004). Beyond educational tourism: Lessons learned while student teaching abroad. International Education Journal, 5(4), 458-465. 
Reyes, L., Quezada, R. L., \& Alfaro, C. (2007). Biliteracy teachers' self-reflections of their accounts while student teaching abroad: Speaking from "the Other Side." Teacher Education Quarterly, Winter, 95-114.

Rong, X. L., \& Preissle, J. (2009). Educating Immigrant Students in the $21^{\text {st }}$ Century: What Educators Need to Know. Thousand Oaks, CA: Corwin.

Sharma, S., Phillion, J., \& Malewski, E. (2011). Examining the practice of critical reflection for developing pre-service teachers' multicultural competencies: Findings from a study abroad program in Honduras. Issues in Teacher Education, 20(2), 9-22.

Shiveley, J., \& Misco, T. (2015). Long-Term Impacts of Short-Term Study Abroad: Teacher Perceptions of Preservice Study Abroad Experiences. Frontiers: The Interdisciplinary Journal of Study Abroad, 26, 107-120.

Stake, R. E. (2006). Multiple case study analysis. New York, NY: Guilford.

Stein, S., Andreotti, V., Bruce, J., \& Suša, R. (2016). Towards different conversations about the internationalization of higher education. Comparative and International Education/Éducation Comparée et Internationale, 45(1), 1-18.

Suarez, D. (2003). The development of empathetic dispositions through global experiences. Educational Horizons, 81(4), 180-82.

Taylor, E. W. (1994). Intercultural competency: A transformative learning process. Adult Education Quarterly, 44, 154-174.

Trilokekar, R. D., \& Kukar, P. (2011). Disorienting experiences during study abroad: Reflections of preservice teacher candidates. Teaching and Teacher Education, 27, 1141-1150.

Valenzuela, A. (1999). Subtractive schooling: US-Mexican youth and the politics of caring. Albany, NY: SUNY Press.

Willard-Holt, C. (2001). The impact of a short-term international experience for pre-service teachers. Teaching and Teacher Education, 17, 505-517.

Yin, R. K. (2009). Case study research: Design and methods (5 ${ }^{\text {th }}$ ed.). Thousand Oaks, CA: Sage Publications.

Zhao, Y. (2010). Preparing globally competent teachers: A new imperative for teacher education. Journal of Teacher Education, 61(5), 422-431.

Zhao, Y., Meyers, L., \& Meyers, B. (2009). Cross-cultural immersion in China: Preparing preservice elementary teachers to work with diverse student populations in the United States. Asia-Pacific Journal of Teacher Education, 37(3), 295-317.

Zinn, H. (1980). A people's history of the United States. New York, NY: Harper and Row. 